\title{
Insightful Analysis of Phenomena Arising at the Metal|Polymer Interphase of Au-Ti Based Non-Enzymatic Glucose Sensitive Electrodes Covered by Nafion
}

\author{
Adrian Olejnik ${ }^{1}$, Jakub Karczewski ${ }^{2}{ }^{\infty}$, Anna Dołęa ${ }^{3}{ }^{\oplus}$, Katarzyna Siuzdak $^{1}$ and \\ Katarzyna Grochowska 1,*(D) \\ 1 Centre for Plasma and Laser Engineering, The Szewalski Institute of Fluid-Flow Machinery, Polish Academy \\ of Sciences, 14 Fiszera St., 80-231 Gdańsk, Poland; adrian.olejnik96@gmail.com (A.O.); \\ ksiuzdak@imp.gda.pl (K.S.) \\ 2 Faculty of Applied Physics and Mathematics, Gdańsk University of Technology, 11/12 Narutowicza St., \\ 80-233 Gdańsk, Poland; jakub.karczewski@pg.edu.pl \\ 3 Department of Inorganic Chemistry, Faculty of Chemistry, Gdańsk University of Technology, 11/12 \\ Narutowicza St., 80-233 Gdańsk, Poland; anna.dolega@pg.edu.pl \\ * Correspondence: kgrochowska@imp.gda.pl
}

Received: 17 July 2020; Accepted: 19 August 2020; Published: 21 August 2020

\begin{abstract}
This paper focuses on the examination of glucose oxidation processes at an electrode material composed of gold nanoparticles embedded in a titanium template. Three different conditions were investigated: the chloride content in the electrolyte, its ionic conductivity and the presence of a Nafion coating. The impact of the provided environment on the oxidation reaction was evaluated by cyclic voltammetry (CV) and electrochemical impedance spectroscopy (EIS). Two models, namely: chemisorption and incipient hydrous oxide/adatom mediator (IHOAM), were applied to explain the complex voltammetric responses of the electrodes exposed to solutions of varied glucose concentrations. Three different phenomena were observed for the studied cases. The first is related to the transition between the dominant mechanism of glucose oxidation from the IHOAM model to the chemisorption model. This happens only in an electrolyte containing chlorides after exceeding a certain amount of glucose. The second effect exhibits a bottleneck nature resulting from the presence of Nafion on the electrode's surface. In this case, mass transport through the semi-permeable polymer is hampered, due to the blocking of channels and physical internal cross-linking. This leads to a preconcentration of glucose inside the pores resulting in an increase in both the material sensitivity and the linear range of the calibration curve. Lastly, the third effect is manifested in a low concentration of the supporting electrolyte. It is based on the fact that mass transport of hydroxyl ions is governed not only by diffusion, but also by migration. These three effects have a tremendous impact on the glucose oxidation mechanism and reveal its very complex nature.
\end{abstract}

Keywords: glucose oxidation mechanism; IHOAM; chemisorption; Nafion coating; Au-Ti heterostructure

\section{Introduction}

Non-enzymatic glucose sensors are still gaining scientific attention, due to the numerous drawbacks of an enzyme-anchored gold substrate acting as the main part of the operating device. They are seen as a prominent path towards breaking the monopoly of rather expensive, enzymatic sensors exhibiting low-stability, and are proposed as an alternative represented by cheaper and easier to fabricate non-enzymatic materials. However, there is still a major problem with their commercial 
application, which is their low selectivity and high susceptibility to biofouling in longer contact with human body fluids [1,2].

There are two methods of increasing selectivity. The first concerns the use of nanostructures e.g., nanoporous Pt [3,4], silica nanochannels [5], copper nanorods [6] and others [1]. The basic idea behind nanostructuring is to tailor the kinetics of the electrochemical process, so that the signal from glucose oxidation is dominant over the many other compounds present in the environment, especially those providing interference. A detailed description concerning the benefits of such kind of materials exhibiting specific nanotextures or/and nanoporosities can be found in the following reviews [1,7].

The second approach is based on coating the electroactive substrate with various polymers acting as a semi-permeable barrier enabling glucose transfer but not allowing for the transport of species affecting the sensing response. Many biocompatible macromolecules were proposed for this function, for example poly(Ethylene Glycol) (PEG) [8], its oligomers [9] and copolymers [10], modified polysaccharides such as chitosan [11], perfluorinated ionomers such as Nafion [12,13] and poly(zwitterionic) coatings based on poly(sulfobetaine methacrylate) (pSBMA) [14] or poly(carboxybetaine methacrylate) (pCBMA) [15]. Nevertheless, most of the performed investigations were simply dedicated to the determination of the sensing parameters, such as the sensitivity or detection limit, but did not focus on the role of the particular coating in the glucose oxidation reaction. Therefore, it is interesting from an electrochemical point of view to examine the processes occurring at the metal/polymer interphase when different concentrations of glucose are introduced to the solution, since the mechanisms covering glucose adsorption and further oxidation can be fairly complicated. Following that, discussion of this matter is still open [1], while a comprehensive analysis can provide important knowledge for further applications.

Regarding the processes occurring at the noble metal surface when the glucose molecule is approaching it, two particular mechanisms of oxidation are known. The first is called the chemisorption model. At moderately low potentials (i.e., $-0.2 \mathrm{~V}$ vs. the reversible hydrogen electrode (RHE)) glucose molecules are adsorbed onto the gold surface in such a geometry that hemiacetal hydrogen is very close to the active metal sites. This hydrogen atom is then prone to be abstracted and simultaneous electron transfer (oxidation) occurs. Finally, an adsorbed intermediate is further oxidized to gluconolactone or similar compounds, which is a step that can occur across a very wide range of potentials, i.e., from +0.4 to $+0.8 \mathrm{~V}$ vs. RHE. At even higher anodic potentials, the gold surface is oxidized, resulting in the formation of gold oxides (III). Glucose can also be oxidized onto the surface of such a layer and the whole process is under diffusion control. In general, the chemisorption model is stereoselective, and $\beta$-glucopyranose is more likely to be chemisorbed and then oxidized $[1,7]$. The abovementioned processes can be described by two equations:

$$
\begin{gathered}
\text { Glucose }_{(a q)} \rightarrow \text { Dehydrogenated Glucose }_{(a d s)}+e^{-} \\
\text {Dehydrogenated Glucose }_{(a d s)} \rightarrow \text { Gluconolactone }_{(a d s)}+e^{-}
\end{gathered}
$$

where $a q$ and $a d s$ correspond to the molecules solvated by water and adsorbed onto the surface of the gold, respectively.

The second mechanism is known as incipient hydrous oxide/adatom mediator (IHOAM). It is based on the idea that a catalytic layer of $\mathrm{Au}(\mathrm{OH})_{\mathrm{ads}}$ is created on the gold surface when the electrode is polarized to moderate anodic potentials (i.e., $+0.3 \mathrm{~V}$ vs. RHE and higher). The presence of $\mathrm{Au}(\mathrm{I})$ species facilitates sluggish oxidation kinetics of organic compounds, e.g., aliphatic alcohols, paracetamol and glucose [1]. Those species act as electron mediators and oxidize glucose to gluconolactone, while the regeneration of the layer results in an oxidation current. The overall process is schematically depicted in Figure 1 and summarized in the below equations:

$$
\begin{gathered}
\text { Glucose }_{(a q)} \leftrightarrows \text { Glucose }_{(a d s)} \\
\text { Glucose }_{(a d s)}+2 \mathrm{AuOH}_{(a d s)} \rightarrow \text { Gluconolactone }+2 \mathrm{Au}
\end{gathered}
$$




$$
\mathrm{Au}+\mathrm{OH}^{-} \rightarrow \mathrm{AuOH}_{(\text {ads })}+e^{-}
$$

The population of adsorbed hydroxyl ions, and therefore the measured current, is likely dependent on the number of surface defects [16], the crystallographic orientation of the metal planes $[17,18]$ and the geometry of the nanostructure $[19,20]$. In the case of some metallic nanomaterials, an additional effect also plays a role, i.e., confined spaces, where the electric field is significantly increased, and can result in a substantial enhancement of the catalytic activity towards glucose [1].

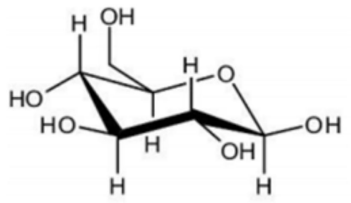

Glucose

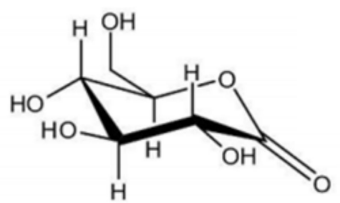

Gluconolactone

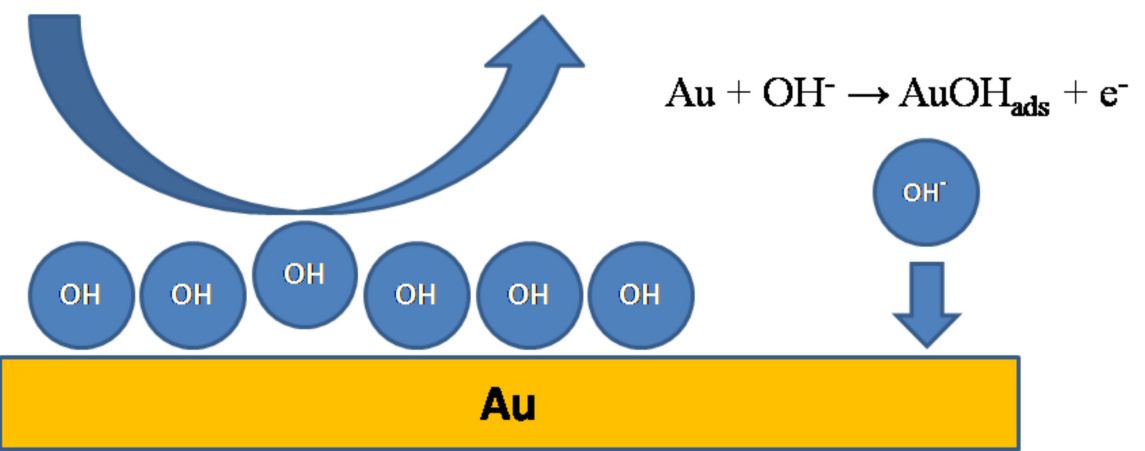

Figure 1. Schematic representation of the incipient hydrous oxide/adatom mediator (IHOAM) model of glucose oxidation on the gold surface.

In our previous works [21-23], we studied electrodes based on gold nanoparticles embedded in a nanostructured titanium template, TiND|AuNP. They exhibited a unique electrochemical response towards glucose in a neutral $\mathrm{pH}$ electrolyte. In particular, a significant change in the shape of the $\mathrm{CV}$ curves was registered when the glucose content in the electrolyte exceeded a certain value, e.g., $0.5 \mathrm{mM}$ for a bare electrode and $1 \mathrm{mM}$ for a Nafion-coated surface. Following that, a unique shape of the calibration curve was obtained, namely two linear ranges were established. It is highly likely that this feature was caused by the change of the glucose oxidation mechanism once the certain concentration threshold was reached. To the best of the authors' knowledge, there are no similar investigations described in the literature for gold-based electrodes.

Therefore, the aim of this paper is to investigate the abovementioned phenomena regarding the glucose oxidation reaction taking place in two electrolytes: commercial phosphate buffer PBS (cPBS) containing chlorides, and a self-made phosphate PBS (sPBS) without chlorides, but with an equal molar concentration of anions. Moreover, the influence of a Nafion coating, as well as the effects of electrolyte conductivity onto the glucose oxidation processes is examined. Nafion is considered here as a model coating, mainly due to its biocompatibility and easy application by evaporation of the solvent. Additionally, it is known that Nafion has the ability to repel negatively charged species form the electrode surface, in particular chloride ions [24,25]. This makes it a promising candidate to verify the influence of chloride ions on the glucose oxidation mechanism. The morphology of the metal electrode is examined by scanning electron microscopy (SEM), while the chemical composition of the coating is confirmed by Fourier-transform infrared spectroscopy (FT-IR). The electrochemical properties are investigated by cyclic voltammetry (CV) and electrochemical impedance spectroscopy (EIS). 


\section{Experimental}

\subsection{Reagents}

Ethylene glycol, ammonium fluoride $\left(\mathrm{NH}_{4} \mathrm{~F}\right)$, oxalic acid, ethanol, acetone and glucose (all pure for analysis) were purchased from Chempur. $1 \mathrm{X}$ Phosphate Buffered Saline (PBS) was supplied by Santa Cruz Biotechnology (137 mM NaCl, $2.7 \mathrm{mM} \mathrm{KCl}, 10 \mathrm{mM} \mathrm{Na}_{2} \mathrm{HPO}_{4}, 10 \mathrm{mM} \mathrm{NaH} \mathrm{PO}_{4}, 1.8 \mathrm{mM}$, $\mathrm{KH}_{2} \mathrm{PO}_{4}$ ) and referred to here as the commercial buffer solution. Perfluorinated resin Nafion solution (30\% in water and lower aliphatic alcohols) was purchased from Aldrich. The water was purified with a Hydrolab HLP-5p device equipped with ion exchange resin.

\subsection{Material Preparation}

The preparation of the TiND|AuNP electrodes is thoroughly described in our previous papers [21,22]. Briefly, a titanium plate $(99.7 \%$, Strem) was ultrasonically cleaned in acetone, ethanol and water. It was then anodized in an ethylene glycol-based electrolyte containing $0.27 \mathrm{M}$ of $\mathrm{NH}_{4} \mathrm{~F}$ and as a result, few-micrometers-long titania nanotubes are formed. The processing parameters were $40 \mathrm{~V}$ and $23^{\circ} \mathrm{C}$ for the applied voltage and electrolyte temperature, respectively. Next, the nanotubes were etched using a diluted oxalic acid solution so that titanium nanodimples were left on the metallic substrate. A thin film of gold $(10 \mathrm{~nm})$ was magnetron sputtered onto the surface of the as-formed nanocavities using a Quorum Technologies Q150S with a highly pure gold target (99.99\%, Quorum). The process was performed in an argon atmosphere at a sputtering rate of $14 \mathrm{~nm} / \mathrm{min}$. The desired thickness was controlled by quartz microbalance. After the deposition, the gold films were thermally dewetted in a muffle furnace for $10 \mathrm{~min}$ at $450^{\circ} \mathrm{C}$ in an air atmosphere (Neoterm Midi Sun K3PX ET, Neoterm, Wrocław, Poland). The selected electrodes were covered by Nafion by simply applying a $30 \mu \mathrm{L}$ droplet of solution. Finally, the electrodes were thermally treated at $120^{\circ} \mathrm{C}$, in order to maintain the adhesion of the coating over the sensing platform during the further electrochemical experiments.

\subsection{Morphology of Electrodes and Chemical Composition of the Nafion Coating}

The morphology of the materials was investigated by means of a Schottky field emission scanning electron microscope (Quanta FEG 250 FEI, Thermo Fisher, Waltham, MA, US) equipped with a secondary electron detector. The accelerating voltage was set to $20 \mathrm{kV}$. The chemical composition of the coating was confirmed by means of Fourier-transform infrared spectroscopy with a Nicolet iS50 FT-IR spectrometer equipped with a diamond attenuated total reflectance (ATR) accessory (ATR Special Quest). The spectra were recorded in the range of $4000-400 \mathrm{~cm}^{-1}$. Analysis of spectral data was performed using the OMNIC software.

\subsection{Electrochemical Measurements}

All cyclic voltammetry and electrochemical impedance spectroscopy experiments were performed using a BioLogic SP-150 potentiostat-galvanostat (BioLogic, Seyssinet-Pariset, France) in a standard three electrode configuration at room temperature. $\mathrm{Ag} / \mathrm{AgCl} / 0.1 \mathrm{M} \mathrm{KCl}$ was used as the reference electrode and a platinum mesh as the counter electrode. The geometric surface area of the working electrodes was between $5 \times 7 \mathrm{~mm}^{2}$ and $5 \times 10 \mathrm{~mm}^{2}$. In the case of the $\mathrm{CV}$, the scan rate was kept constant at $50 \mathrm{mV} / \mathrm{s}$ and the electrolytes consisted of $0.1 \mathrm{X}$ cPBS $(13.7 \mathrm{mM} \mathrm{NaCl}, 0.27 \mathrm{mM} \mathrm{KCl}, 1.0 \mathrm{mM}$ $\left.\mathrm{Na}_{2} \mathrm{PO}_{4}, 1.0 \mathrm{mM} \mathrm{NaHPO}, 0.18 \mathrm{mM} \mathrm{KH}_{2} \mathrm{PO}_{4}\right)$ or $0.01 \mathrm{M}$ and $0.1 \mathrm{M} \mathrm{sPBS}\left(10 \mathrm{mM} \mathrm{Na} 2 \mathrm{HPO}_{4}\right.$ and $10 \mathrm{mM}$ $\mathrm{NaH}_{2} \mathrm{PO}_{4}$ ). It should be emphasized that $0.1 \mathrm{X}$ cPBS contained a similar amount of ions as $0.01 \mathrm{M}$ sPBS without chlorides, i.e., $20 \mathrm{mM}$ of all anions summed. In the case of the EIS, a frequency range of $10 \mathrm{kHz}-100 \mathrm{mHz}$ and a potential of $10 \mathrm{mV}$ sinusoidal perturbation were used. The electrolytes used were $1 \mathrm{X}$ cPBS or $0.1 \mathrm{M}$ sPBS with dissolved $10 \mathrm{mM}$ of potassium hexacyanoferrate (III) $\mathrm{K}_{3}\left[\mathrm{Fe}(\mathrm{CN})_{6}\right]$ and potassium hexacyanoferrate (II) $\mathrm{K}_{4}\left[\mathrm{Fe}(\mathrm{CN})_{6}\right]$. The use of higher concentrations was required to ensure proper ionic conductivity. Following that, the spectra were recorded at the formal potential of the ferrocyanide redox pair. The impedance data was analyzed based on the complex nonlinear least 
squares (CNLS) procedure to the equivalent circuit using the Powell algorithm in the EIS Spectrum Analyser software [26]. Glucose concentrations were chosen so that the transition between glucose oxidation mechanisms could be detected. The lower limit was set to $0.1 \mathrm{mM}$ of glucose while upper limit depended on the observed phenomena.

\section{Results and Discussion}

\subsection{Morphology of Electrodes and Chemical Composition of the Nafion Coating}

After the thermal dewetting of the thin gold films deposited onto the titanium dimpled template, regular arrays of gold nanoparticles embedded in semispherical hosting wells are obtained (Figure 2a). The size of the nanoparticles was $85 \pm 10 \mathrm{~nm}$ and they had mostly circular shapes. The influence of various parameters on the morphology has been already discussed in detail in our previous works [21,22], and here we will not focus deeply on the surface analysis. This TiND|AuNP electrode was formed as a result of the optimized fabrication route. The FT-IR spectrum of the TiND|AuNP electrode covered with Nafion is presented in Figure 2b. One can easily see the characteristic absorption bands confirming the proper formation of the polymer coating over the metallic surface. They are in agreement with other studies of Nafion coatings $[27,28]$, and the identified bands are collected in Table 1.
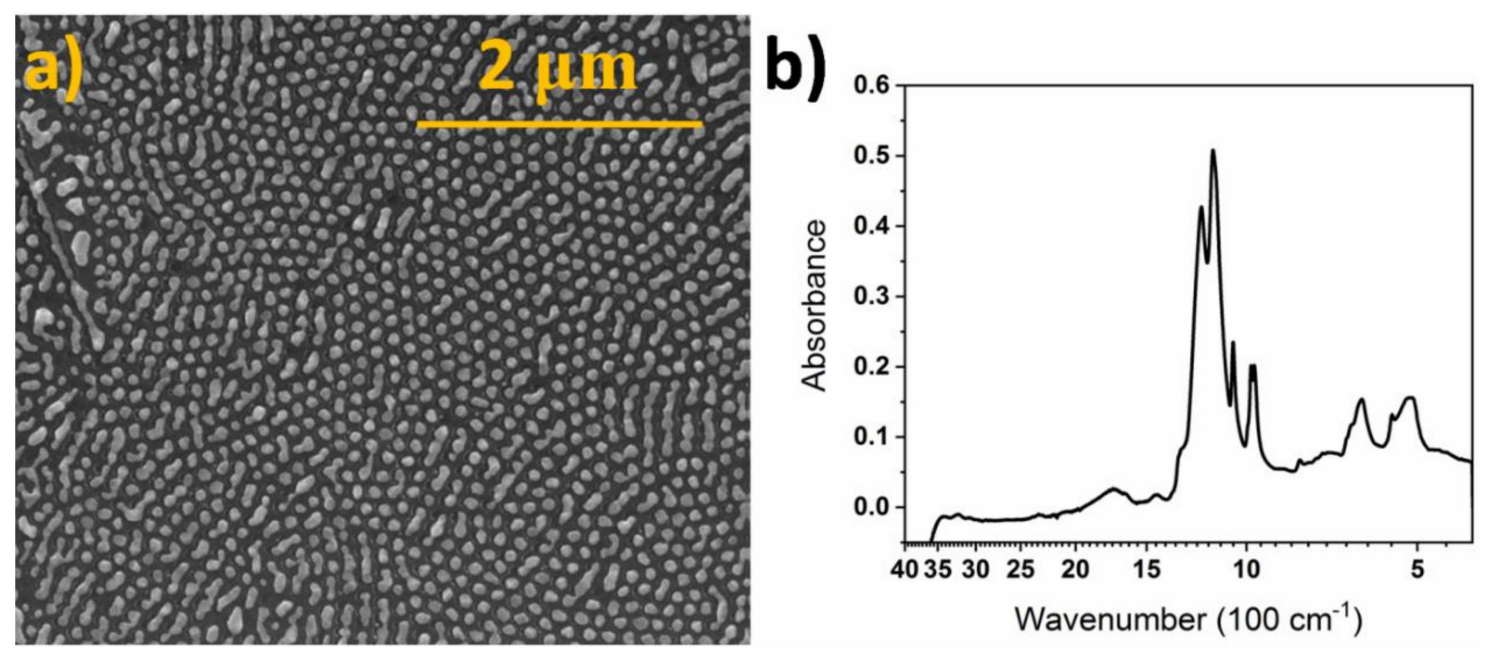

Figure 2. (a) Scanning electron microscopy (SEM) image of TiND|AuNP electrode, (b) Fourier-transform infrared spectroscopy (FT-IR) spectrum of TiND|AuNP electrode covered with Nafion.

Table 1. Characteristic IR bands found for Nafion coating [27,28].

\begin{tabular}{cc}
\hline Wavenumber $\left[\mathrm{cm}^{-1}\right]$ & Corresponding Vibrations \\
\hline 620 & $\mathrm{CF}_{2}$ wagging \\
\hline 970 & $\mathrm{C}-\mathrm{O}-\mathrm{C}$ symmetric stretching \\
\hline 1060 & $\mathrm{SO}_{3}{ }^{-}$symmetric stretching \\
\hline 1140 & $\mathrm{CF}_{2}$ asymmetric stretching \\
\hline 1200 & $\mathrm{SO}_{3}{ }^{-}$asymmetric stretching and $\mathrm{CF}_{2}$ asymmetric stretching \\
\hline
\end{tabular}

\subsection{Electrode Behavior in Commercial and Self-Made PBS}

Cyclic voltammograms of the bare TiND|AuNP electrodes recorded in $0.1 \mathrm{XcPBS}$, as well as the calibration curve, are given in Figure 3. One can see that in the lower concentrations regime, the CV curves consisted of small glucose oxidation peaks at the potential of $+0.22 \mathrm{~V}$ (oxidation of glucose to gluconolactone-labelled as peak 1 in Figure 3 ) and gold oxide formation plateaus found at $+0.5 \mathrm{~V}$ 
(peak 2, oxidation of $\mathrm{AuOH}_{\mathrm{ads}}$ to $\mathrm{Au}$ (III) species) and higher potentials up to $+1.2 \mathrm{~V}$ in the anodic branch. In the cathodic branch, gold oxide (III) reduction to $\mathrm{AuOH}_{\text {ads }}$ occurred at $+0.2 \mathrm{~V}$ (peak 3 ) and the further reduction of gold (I) to $\mathrm{Au}(0)$ and titanium (IV) oxides to Ti (III) species took place at $-0.3 \mathrm{~V}$ (peak 4) and extended to lower potentials up to $-1.0 \mathrm{~V}$. As the glucose concentration increased, several significant changes could be observed. Namely, after exceeding $0.5 \mathrm{mM}$, an additional oxidation peak at $-0.4 \mathrm{~V}$ (peak 5) appeared and systematically grew in both the anodic and cathodic branches with the higher analyte content. Considering the similarity of the oxidation potentials, it resembled the hemiacetal hydrogen abstraction peak in the chemisorption mechanism. In the later paragraphs, this hypothesis will be addressed many times and supported by other arguments. Additionally, other oxidation peaks appeared in the higher anodic regime, at $+0.9 \mathrm{~V}$, and their intensity grew along with the glucose concentration. The main glucose oxidation peak located at $+0.25 \mathrm{~V}$ also increased with the concentration, but after exceeding $0.5 \mathrm{mM}$, it also shifted to higher potentials up to $+0.35 \mathrm{~V}$. Moreover, an additional small local maximum at $+0.15 \mathrm{~V}$ was present. The increase of the current density of the peak attributed to glucose oxidation was not linear within the whole investigated glucose range, and one could distinguish two regimes with different slopes: $29.3 \mu \mathrm{A} \mathrm{cm}^{-2} \mathrm{mM}^{-1}$ for $0.1-0.5 \mathrm{mM}$ and $3.5 \mu \mathrm{A} \mathrm{cm}^{-2} \mathrm{mM}^{-1}$ for $1.0-10 \mathrm{mM}$. The changes in the shape of the voltammograms correspond to the slope variation. The described behavior suggests that in the higher concentrations regime, two mechanisms—chemisorption and IHOAM_occur at the same time, while, unexpectedly, the chemisorption dominates.
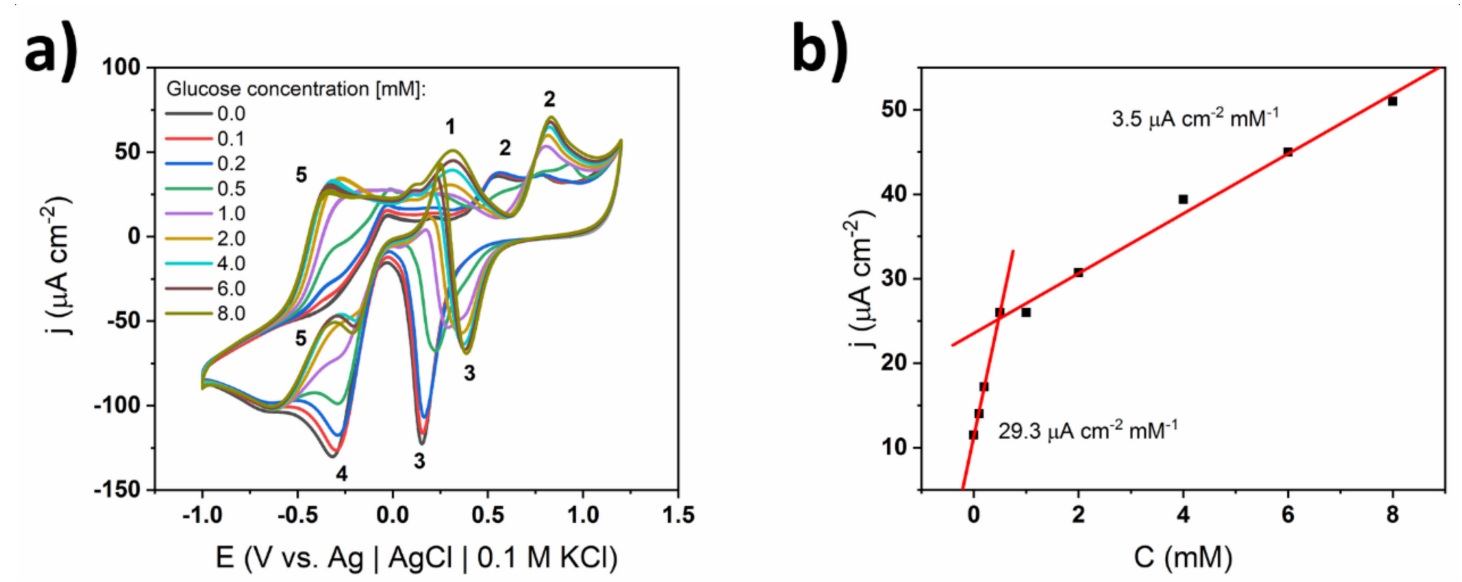

Figure 3. (a) Cyclic voltammograms of TiND|AuNP uncoated electrode registered for different glucose concentrations in $0.1 \mathrm{X}$ commercial phosphate buffer PBS (cPBS), (b) calibration curve based on glucose oxidation peak at $+0.35 \mathrm{~V}$.

A similar experiment was performed in the electrolyte containing the same amount of ions, but in $0.01 \mathrm{M}$ sPBS, where the chlorides were substituted with the excess of phosphate ions (Figure 4). Surprisingly, the number and shape of the oxidation and reduction peaks on the CV curves were exactly the same in the whole glucose concentration range. One can see that the main glucose oxidation peak was located at $+0.3 \mathrm{~V}$ and its potential was constant. Similarly, a broad shoulder at ca. $+0.05 \mathrm{~V}$ and a gold oxide formation peak at $+0.7 \mathrm{~V}$ can be observed. In the case of the sPBS electrolyte, anodic polarization higher than $+0.9 \mathrm{~V}$ cannot be reached, due to the fact that oxygen evolution occurs. Compared to the cPBS conditions, the upper limit of linear response is significantly extended from 0.5 to $3 \mathrm{mM}$. There is, however, a slow decrease of the slope value indicating the saturation of the gold active sites [29]. This can also be assigned to other effects arising at higher glucose levels. When the glucose concentration reaches a few millimoles, diffusion is no longer a dominant method of mass transport and the migration part in the Nernst-Planck equation also becomes crucial [30,31]. This happens because the concentration of the supporting electrolyte is similar to the glucose content and the scan rate is kept constant at $50 \mathrm{mV} / \mathrm{s}$. Generally, although the linear range is limited to $3 \mathrm{mM}$, 
no transition in the glucose oxidation mechanism is observed. One can therefore conclude that chloride ions are responsible for the mechanism change.
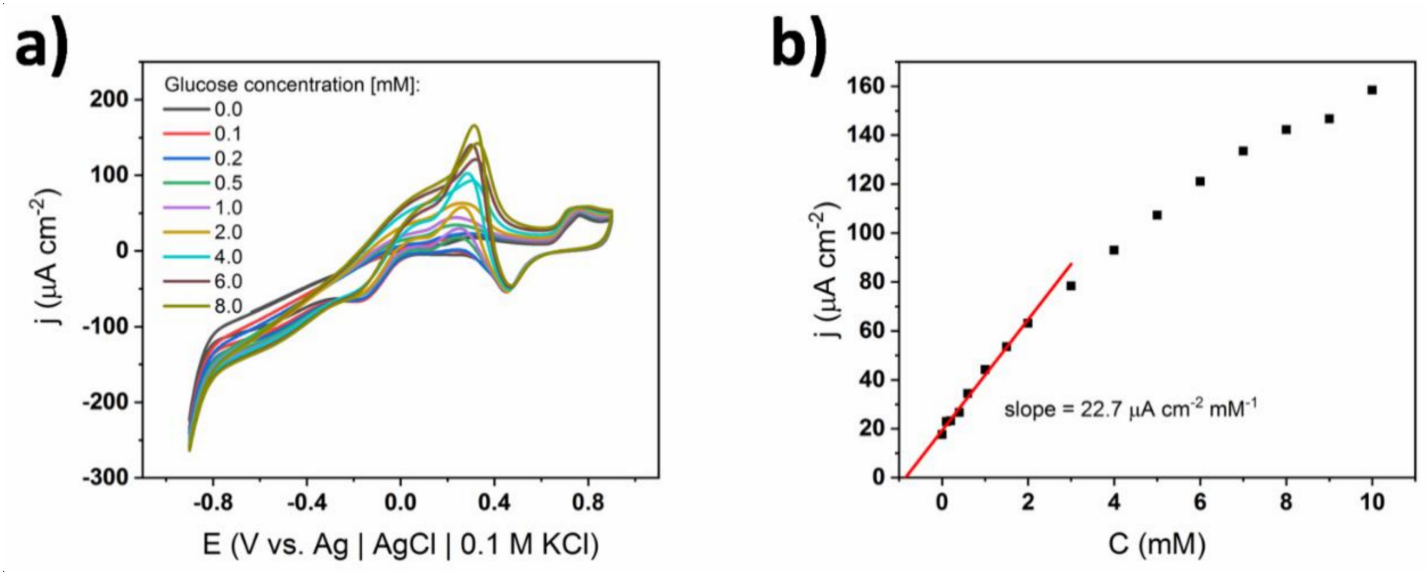

Figure 4. (a) Cyclic voltammograms of bare TiND|AuNP electrode registered for different glucose concentrations in $0.01 \mathrm{M}$ self-made phosphate PBS (sPBS), (b) calibration curve depicting the change of the current density at the glucose oxidation peak $(+0.35 \mathrm{~V})$.

To investigate the differences between the material's performance in two electrolytes, EIS experiments in the presence of a ferrocyanide redox pair (Figure 5) were performed. In order to obtain spectra of good quality, the concentrations of both the commercial and self-made phosphate buffers were increased 10 -fold to $1 \mathrm{M}$, providing higher ionic conductivity of the solution. In this type of measurement, ferrocyanides can be treated as probe electroactive molecules that allow the surface states to be investigated [32]. One can see that after injecting the first portion of glucose, both oxidation and reduction peaks increased slightly and maintained their position and current density values for larger glucose concentrations. The peaks were symmetric in size and shape, and difference between the oxidation and reduction signals was $150 \mathrm{mV}$. Besides the relatively large value of this potential gap, the ferrocyanide redox reaction can be treated as reversible.
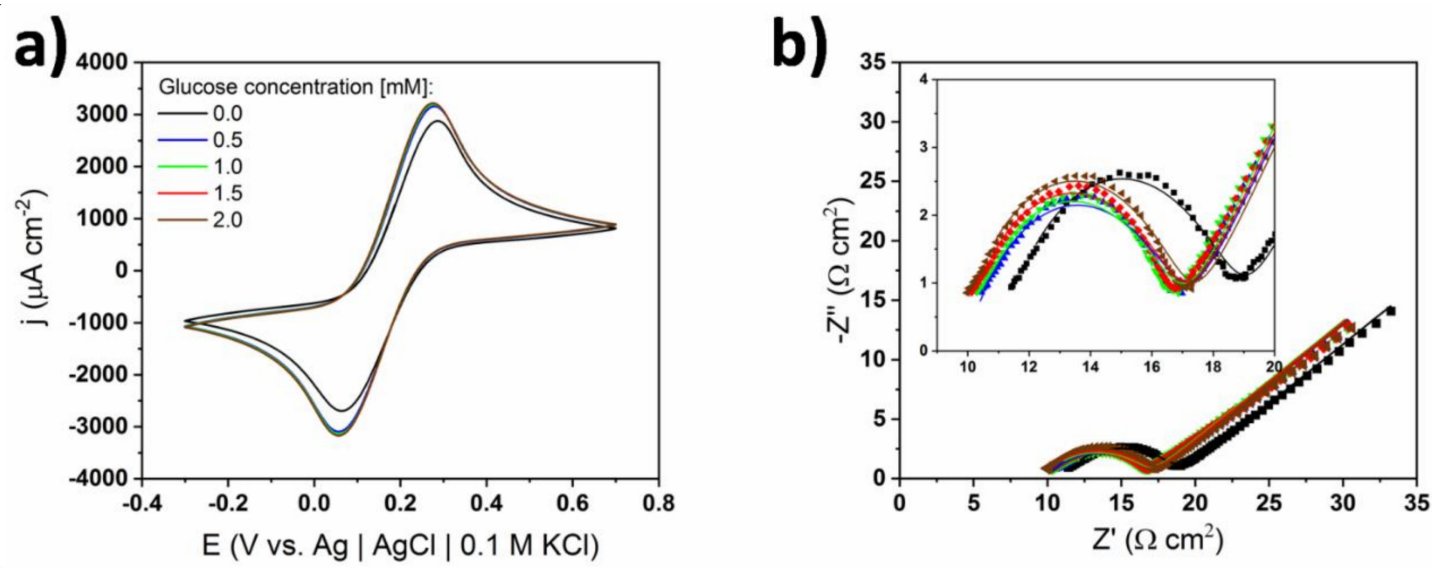

Figure 5. (a) Cyclic voltammograms, and (b) electrochemical impedance spectroscopy (EIS) spectra of bare TiND|AuNP electrode registered for different concentrations of glucose in $1 \mathrm{X}$ cPBS containing 10 $\mathrm{mM}$ of ferrocyanide redox pair; inset-magnification in the $10-20 \Omega \mathrm{cm}^{2}$ range. Dotted lines correspond to measured impedance data and continuous lines to fitted data.

The EIS spectra consisted of semicircles at a higher frequency range and straight lines with almost $45^{\circ}$ slopes at a lower frequency range. The centers of those semicircles lie below the real axis indicating the need of using a constant phase element (CPE) in the equivalent circuit [32]. One can see that upon injection of the first glucose portion, the spectrum shifted to lower real impedance 
values. However, the rest of the spectra-i.e., all spectra for electrolytes containing glucose in the $0.5 \mathrm{mM}-2.0 \mathrm{mM}$ range- did not change with the increase of glucose content. Only a slight increase in the height of the maximum was noted. This could indicate a successive increase of double layer capacitance. Considering the relatively high concentration of the supporting electrolyte, the measured capacitance came rather from the Helmholtz double layer, not the diffusive layer [30,31]. A Randles circuit with a CPE element was chosen as the equivalent circuit for the fitting procedure-see Figure 6. The impedance of the CPE element is the following:

$$
Z=\frac{1}{Q_{0}(j \omega)^{n}}
$$

where is imaginary unit, $\omega$ is an angular frequency, $Q_{0}$ is a parameter related to the double layer capacitance, and $n$ is a CPE constant describing the deviation of this element from being an ideal capacitor $(n=1)$. The fitting results together with goodness values are given in Table 2 . The double layer capacitance was calculated according to the Hsu and Mansfeld equation [33]:

$$
C_{d l}=Q_{0}\left(\omega_{\max }\right)^{n-1}
$$

where $\omega_{\max }$ is the frequency value where the imaginary part has its maximum. As suggested from the brief analysis of spectra, all of the fitted elements' values did not change significantly with the glucose concentration. This means that the redox reaction of the ferrocyanide redox pair was not altered by the presence of glucose. Considering Equations (1) and (2), one can see that if glucose is oxidized via the chemisorption model, it is adsorbed on gold through charge transfer reactions. At the potential used during the EIS experiments (i.e., $+0.22 \mathrm{~V}$ ), hydrogen abstraction and chemisorption do not occur, so that the only studied process is the ferrocyanides redox reaction. Therefore, results of the EIS analysis seem to support the hypothesis that the glucose oxidation mechanism in the solution containing chlorides (cPBS) happened rather via the chemisorption mechanism on the TiND|AuNP electrodes.

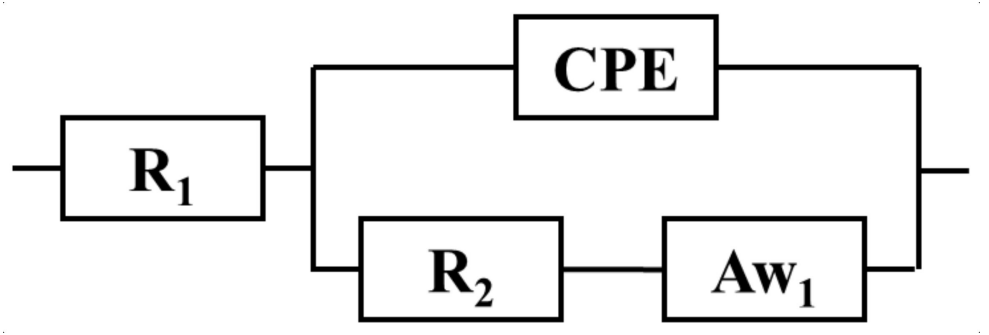

Figure 6. Randles equivalent circuit. $R_{1}$ is solution resistance, $R_{2}$-charge transfer resistance, and $\mathrm{Aw}_{1}$-Warburg semi-infinite linear diffusion element.

Table 2. Equivalent circuit parameters obtained from fitting procedure applied to EIS spectra recorded in cPBS (see Figure 5b).

\begin{tabular}{cccccc}
\hline Parameters & $\begin{array}{c}\mathbf{0 . 0} \mathbf{~ m M} \\
\text { Glucose }\end{array}$ & $\begin{array}{c}\mathbf{0 . 5} \mathbf{~ m M} \\
\text { Glucose }\end{array}$ & $\begin{array}{c}\mathbf{1 . 0} \mathbf{m M} \\
\text { Glucose }\end{array}$ & $\begin{array}{c}\mathbf{1 . 5} \mathbf{~ m M} \\
\text { Glucose }\end{array}$ & $\begin{array}{c}\mathbf{2 . 0} \mathbf{~ m M} \\
\text { Glucose }\end{array}$ \\
\hline $\mathrm{R}_{1}\left[\Omega \mathrm{cm}^{2}\right]$ & 11.0 & 10.0 & 9.8 & 9.7 & 9.6 \\
\hline $\mathrm{R}_{2}\left[\Omega \mathrm{cm}^{2}\right]$ & 7.8 & 7.1 & 7.0 & 7.3 & 7.5 \\
\hline $\mathrm{Aw}_{1}\left[\Omega \mathrm{cm}^{2} \mathrm{~s}^{1 / 2}\right]$ & 11.47 & 10.6 & 10.6 & 10.6 & 10.5 \\
\hline$Q_{0}$ & 134 & 194 & 161 & 144 & 119 \\
\hline$n$ & 0.72 & 0.68 & 0.70 & 0.72 & 0.74 \\
\hline$C_{d l}\left[\mu \mathrm{F} \mathrm{cm}{ }^{-2}\right]$ & 9.6 & 9.1 & 9.2 & 9.9 & 10.3 \\
\hline$\chi^{2} / 10^{-4}$ & 0.795 & 2.0 & 1.3 & 1.3 & 1.1 \\
\hline
\end{tabular}


In the case of the measurements performed in SPBS without chlorides, there are significantly different trends in the changes of the CV curves and EIS spectra recorded in different glucose contents (see Figure 7). First of all, while adding more and more glucose, one can observe the decreasing of both the oxidation and reduction peaks of the ferrocyanides. Moreover, the difference between the peak potentials increased rapidly, indicating that the redox processes were less reversible when more glucose was introduced to the solution. As higher amounts of glucose molecules were adsorbed on the gold surface, the number of available electroactive sites where the ferrocyanide redox reaction could be carried out reduced. Therefore, the speed of the charge transfer was hampered [30]. This stands in agreement with the fact that when no chlorides were present in the electrolyte, the glucose oxidation proceeded according to the IHOAM model.
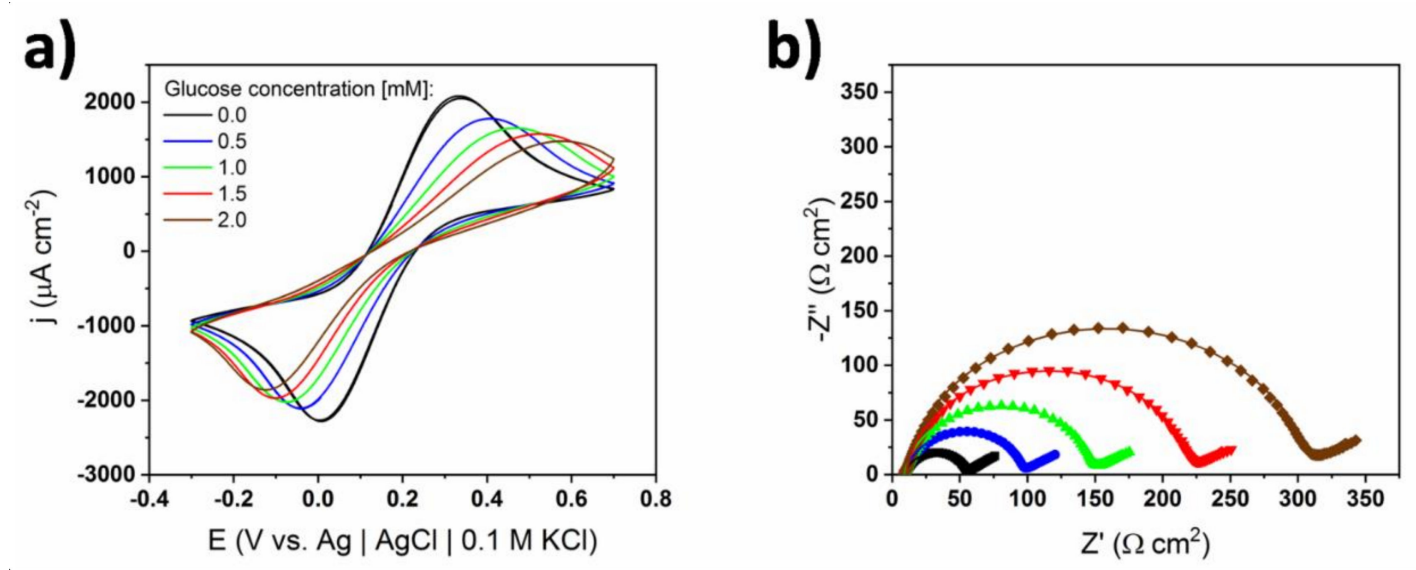

Figure 7. (a) Cyclic voltammograms, and (b) EIS spectra of bare TiND|AuNP electrode registered for different concentrations of glucose in $0.1 \mathrm{M}$ sPBS containing $10 \mathrm{mM}$ of ferrocyanide redox pair. Dotted lines correspond to measured impedance data and continuous lines to fitted data.

The results obtained from the EIS spectra also support the proposed hypothesis. The parameters acquired by the fitting procedure with the use of the same Randles circuit are given in Table 3 . One can see that, in this case, adding glucose impacted the ferrocyanide redox reaction. First, the charge transfer resistance, which is inversely proportional to the kinetic constant [32], increased with the glucose concentration. Secondly, the Warburg impedance increased with the glucose concentration, which stands for decreasing of the diffusion coefficient [32]. One can conclude that glucose adsorption inhibits the charge transfer of ferrocyanides and reduces their apparent diffusion coefficients. The decrease of the diffusion coefficients can be ascribed to the fact that, during the experiment, larger and larger amounts of glucose were adsorbed and present in the double layer [34]. The high concentration of glucose molecules in the double layer could have acted as a barrier to the ferrocyanides, therefore slowing their diffusion to the electroactive part of the electrode. Considering Equation (3) in the IHOAM model, glucose was adsorbed on the metal surface without charge transfer, i.e., it could happen regardless of the applied potential [31]. In the sPBS devoid of chlorides, glucose could be adsorbed this way while oxidation happened most probably through the IHOAM model. According to [35], when gold is immersed in $\mathrm{KCl}$, its surface is passivated and $\mathrm{AuCl}_{\text {ads }}$ species are mostly created, which are not capable towards glucose oxidation. A similar phenomenon might have happened in the case of the CPBS. The presence of chlorides in the cPBS solution resulted in the formation of $\mathrm{AuCl}_{\mathrm{ads}}$ on the surface of the gold nanoparticles instead of $\mathrm{AuOH}_{\mathrm{ads}}$, leading to the changes in the oxidation mechanism. As a result of this, glucose molecules could not be oxidized through the IHOAM model. In the following case chemisorption occurred. 
Table 3. Equivalent circuit parameters obtained from fitting procedure applied to EIS spectra recorded in sPBS (see Figure 7b).

\begin{tabular}{cccccc}
\hline Parameters & $\begin{array}{c}\mathbf{0 . 0} \mathbf{M m} \\
\text { Glucose }\end{array}$ & $\begin{array}{c}\mathbf{0 . 5} \mathbf{~ m M} \\
\text { Glucose }\end{array}$ & $\begin{array}{c}\mathbf{1 . 0} \mathbf{~ m M} \\
\text { Glucose }\end{array}$ & $\begin{array}{c}\mathbf{1 . 5} \mathbf{~ m M} \\
\text { Glucose }\end{array}$ & $\begin{array}{c}\mathbf{2 . 0} \mathbf{~ m M} \\
\text { Glucose }\end{array}$ \\
\hline $\mathrm{R}_{1}\left[\Omega \mathrm{cm}^{2}\right]$ & 9.2 & 9.8 & 9.3 & 10.5 & 10.1 \\
\hline $\mathrm{R}_{2}\left[\Omega \mathrm{cm}^{2}\right]$ & 45.8 & 87.0 & 139.0 & 209.0 & 294.3 \\
\hline $\mathrm{Aw}_{1}\left[\Omega \mathrm{cm}^{2} \mathrm{~s}^{1 / 2}\right]$ & 14.7 & 15.8 & 17.3 & 19.5 & 24.5 \\
\hline$Q_{0}$ & 29.2 & 23.2 & 22.0 & 20.8 & 20.8 \\
\hline$n$ & 0.90 & 0.92 & 0.93 & 0.94 & 0.94 \\
\hline$C_{d l}\left[\mu \mathrm{F} \mathrm{cm}{ }^{-2}\right]$ & 14.0 & 13.6 & 14.2 & 14.7 & 15.0 \\
\hline$\chi^{2} / 10^{-3}$ & 2.8 & 3.5 & 6.9 & 6.0 & 9.2 \\
\hline
\end{tabular}

Summarizing the section dedicated to the investigation of nature of the calibration curve, the switching from the IHOAM to the chemisorption model as the dominating mechanism of glucose oxidation occurred when the concentration of glucose exceeded $0.5 \mathrm{mM}$. This transition was caused by chloride ions present in the commercial phosphate buffer, which adsorbed on the surface of the gold, reducing the number of $\mathrm{AuOH}_{\text {ads }}$ catalytic sites playing an important role in glucose oxidation. It is schematically presented in Figure 8.

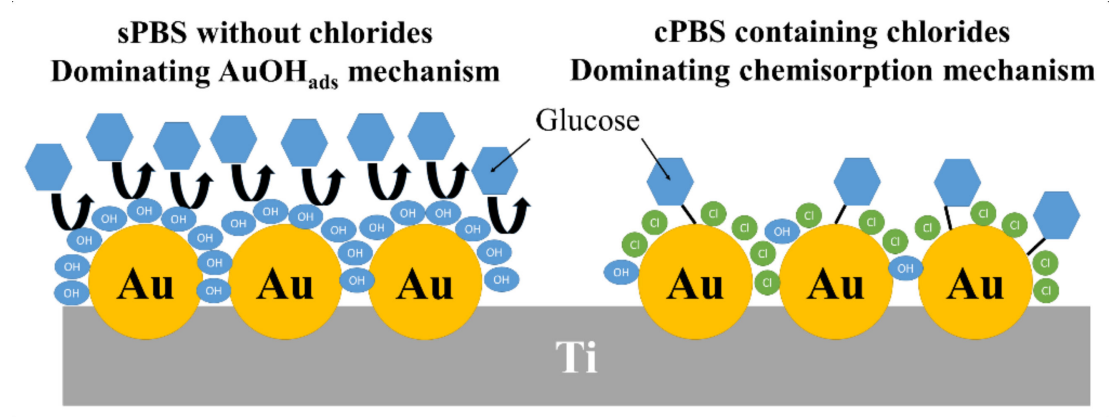

Figure 8. Schematic illustration of the effect of chloride ions contained in cPBS on the mechanism of glucose oxidation.

\subsection{Influence of Nafion Coating on the Calibration Curve}

Another aim of this paper is to investigate the impact of Nafion as a protective film on the electrochemical response and calibration curves as well as the switching between the mechanisms describing the glucose oxidation. It is known that besides ion exchanging properties, Nafion possesses a unique morphology when in contact with an aqueous solution. It consists of polymeric domains of a size between a few and a few tens of nanometers as well as pores and channels between them. These channels are negatively charged due to the presence of $-\mathrm{SO}_{3}{ }^{-}$groups in pendant chains and large numbers of $-\mathrm{CF}_{2}{ }^{-}$and $-\mathrm{CF}_{3}$ groups in both main and pendant chains. The explicit form of this structure is highly dependent on the molecular mass distribution and preparation method [25]. Due to the presence of pores and channels, glucose is capable of penetrating the membrane and blocking other potential interference as well $[12,13,23]$. Moreover, if the switching is indeed caused by chloride ions, its effects should be minimized, due to repelling of anions by the Nafion [24,25].

The CV curves for membrane-coated TiND|AuNP electrodes registered in different glucose concentrations along with the calibration curve are shown in Figure 9. In the range of the lower concentrations, i.e., $10-1000 \mu \mathrm{M}$, a glucose oxidation peak at $+0.2 \mathrm{~V}$ was present similarly to the electrode without the Nafion coating. After exceeding $2 \mathrm{mM}$ of glucose, a hydrogen abstraction peak at $-0.4 \mathrm{~V}$ emerged, however it was relatively lower for the membrane-coated electrode. Interestingly, the main oxidation peak at $+0.2 \mathrm{~V}$ increased with the concentration until $4 \mathrm{mM}$ of glucose was reached. 
Then, the current density rapidly dropped and after exceeding $15 \mathrm{mM}$, it again rose. In contrast to the bare electrode, its potential gradually shifted from +0.2 to $+0.35 \mathrm{~V}$, while the glucose content was increasing in the range of $4-15 \mathrm{mM}$. It can be postulated that besides the transition between mechanisms, another effect played important role, namely the transfer of analyte through the channels in the structure was hampered as its concentration increased [36]. Moreover, a diffusion-controlled oxidation peak at $+0.9 \mathrm{~V}$ appeared at a relatively large concentration of glucose $(11 \mathrm{mM})$, while gold oxide reduction was also anodically shifted, and therefore, another glucose oxidation peak was emerging. The variety of observed changes in the electrochemical activity (i.e., potential shifts at higher concentrations) supports the statement that Nafion minimizes the effects related to the switching of the glucose oxidation mechanism.
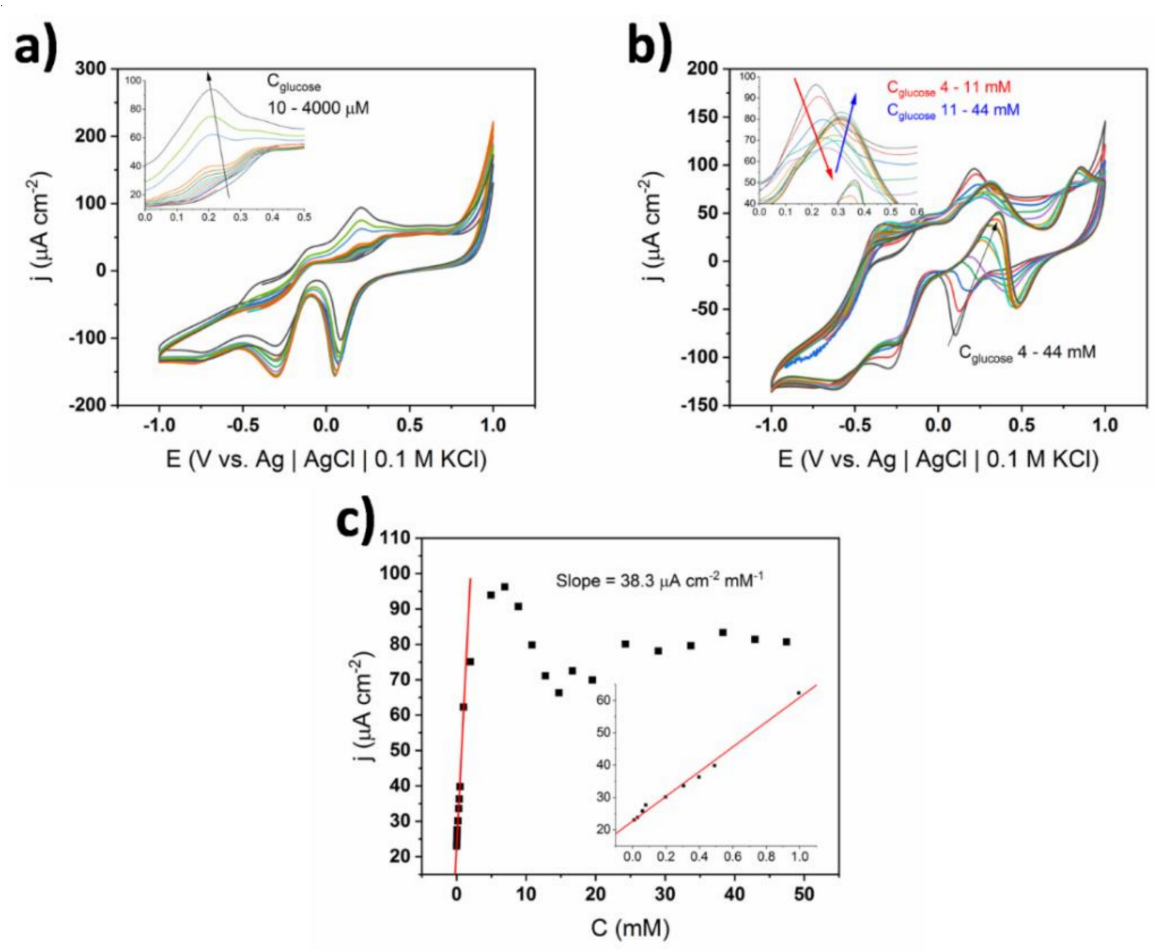

Figure 9. (a) and (b) Cyclic voltammograms of TiND|AuNP Nafion-coated electrode registered for different glucose concentrations in $0.1 \mathrm{X}$ cPBS; insets-magnification of glucose oxidation peaks, (c) calibration curve based on glucose oxidation peak at $+0.35 \mathrm{~V}$.

The increase in sensitivity of the Nafion-coated substrate from 29.3 to $38.3 \mu \mathrm{A} \mathrm{cm}-2 \mathrm{mM}^{-1}$ can be explained by the preconcentration effect, which is known in ion exchange voltammetry for polymer-coated electrodes [36]. This phenomena is based on the equilibrium between the analyte molecules in the solution and inside the membrane. The selectivity coefficient (equilibrium constant) is given by:

$$
K \cong \frac{[\text { Glucose }]_{\text {Nafion }}}{[\text { Glucose }]_{a q}}
$$

If $K$ is greater than 1, concentration of glucose inside the Nafion can be higher than in the bulk electrolyte. According to [36], Nafion is capable of preconcentrating different electroactive species. It could be stated that glucose can also be locked in channels and pores of Nafion, in a similar way to small cations and cationic complexes. The local concentration is then increased and, in consequence, 
the recorded faradaic current is enhanced. The proposed explanation can be supported by an analysis of the equation relating the peak currents for the same process at coated and non-coated electrodes [37]:

$$
\frac{I_{\text {coated }}}{I_{\text {bare }}}=K \sqrt{\frac{D_{\text {coated }}}{D_{\text {bare }}}}
$$

Herein, the ratio between the peak currents is roughly equal to 1 . The diffusion coefficient in a polymer is typically a few times smaller $\left(5 \times 10^{-6} \mathrm{~cm}^{2} \mathrm{~s}^{-1}\right.$ in calcium alginate membranes [38] or $1 \times 10^{-6} \mathrm{~cm}^{2} \mathrm{~s}^{-1}$ in poly (acrylamide) gels [39]) than in water solutions $\left(7 \times 10^{-6} \mathrm{~cm}^{2} \mathrm{~s}^{-1}\right.$ [39]). Therefore, constant $\mathrm{K}$ must be in the range of 2-3, meaning that the preconcentration effect occurs in the case of the TiND|AuNP|Nafion electrode. It is also connected with the bottleneck effect observed in fluoropolymers reported as early as the 1980s [40]. Therefore, constant K must be in the range of 10-100, meaning that the preconcentration effect occurs in the case of the TiND|AuNP|Nafion electrode. The widening of the linear range is a natural consequence of the fact that the diffusion layer is much smaller than the coating thickness. The apparent diffusion coefficient of glucose in Nafion is smaller, compared to the diffusion coefficient in solution. Therefore, when an electrode is coated, there is a wider range of glucose concentrations, where diffusion is the rate determining a step of the overall process [36]. The unusual behavior of the CV curves in the following experiment indicated that glucose oxidation processes on protected metal electrodes are far more complex than is commonly described.

Analogous CV scans and the calibration curve for Nafion-coated TiND|AuNP electrodes were performed in $0.01 \mathrm{M} \mathrm{sPBS}$ and are presented in Figure 10. One can see that across the whole concentration range, the glucose oxidation currents took the shape of quite wide and slight peaks-similar to the CV curves in Figure 9-for very low glucose content. The potential of glucose oxidation maximum remained constant at $+0.25 \mathrm{~V}$. Interestingly, after exceeding $1 \mathrm{mM}$ of glucose, two oxidation peaks emerged at -0.45 and $+0.9 \mathrm{~V}$, suggesting that chemisorption can also occur. Nevertheless, the linear range of the relation between the glucose oxidation current and the glucose level reached an upper limit of $3 \mathrm{mM}$, similarly to the one shown in Figure 4. This suggests that the IHOAM model was still dominant. In the case of the CPBS, the slope value was greater when Nafion was introduced onto the surface. Regarding the sPBS, the sensitivity was reduced to $10.5 \mu \mathrm{A} \mathrm{cm}^{-2} \mathrm{mM}^{-1}$ compared to the bare electrode. Such behavior may be explained by the reduction of catalytic activity, due to the adsorption of different phosphate ions on the gold surface [41].
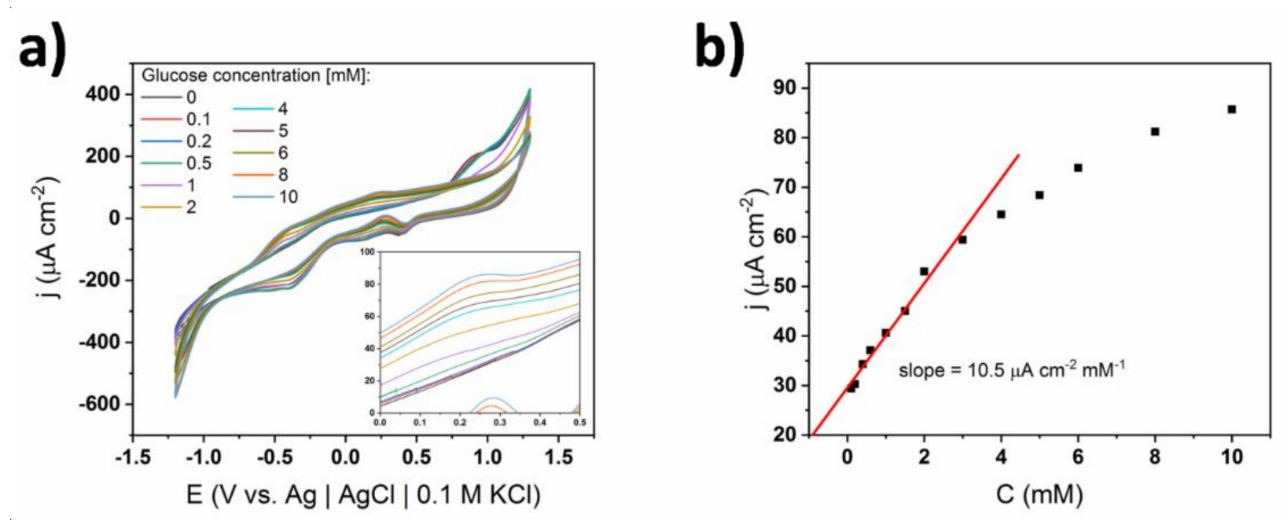

Figure 10. (a) Cyclic voltammograms of TiND|AuNP Nafion-coated electrode registered for different glucose concentrations in $0.01 \mathrm{M}$ sPBS; inset-magnification of glucose oxidation peaks, (b) calibration curve based on glucose oxidation peak at $+0.35 \mathrm{~V}$.

Taking into account the gathered results, when the permeable membrane protects the TiND|AuNP platform, it can be stated that Nafion increases the sensitivity and widens the linear range owing to the preconcentration effect. This phenomenon makes the transition between mechanisms more smooth, compared to the bare electrode conditions. Due to bottleneck effect, when the glucose exceeds $4 \mathrm{mM}$, 
the oxidation current drops, along with changes to the chemisorption model. The effect of the Nafion coating on the concentration of glucose is schematically presented in Figure 11.

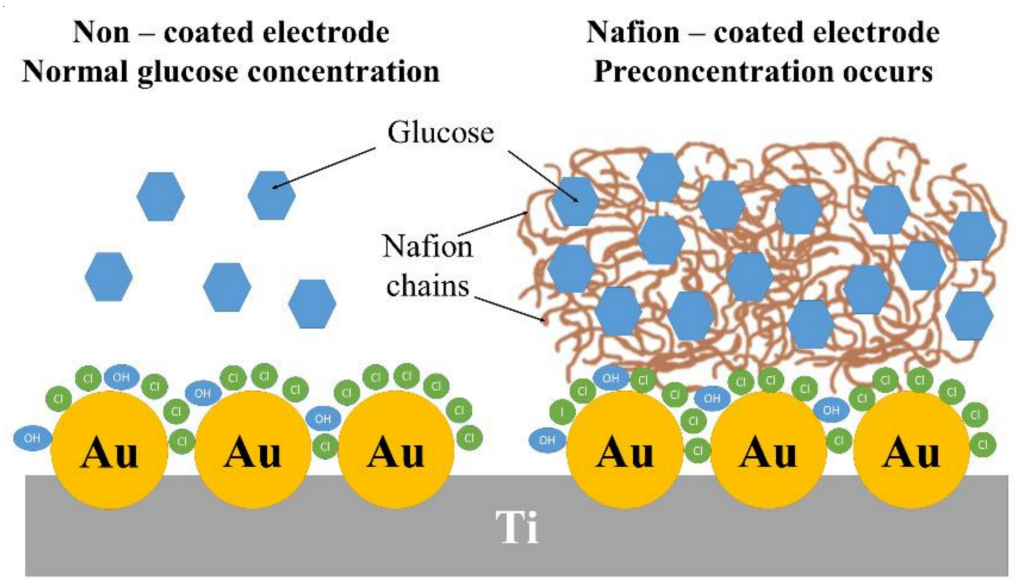

Figure 11. Schematic illustration of the effect of Nafion coating on the concentration of glucose in the vicinity of the electrode.

\subsection{Influence of Ionic Conductivity of the Solution on the Electrochemical Response}

Finally, the influence of the ionic conductivity of the supporting electrolyte on the shape of the CV curves and the resulting calibration curves were evaluated. The cyclic voltammograms for a non-coated electrode immersed in $0.1 \mathrm{M}$ concentrated sPBS are shown in Figure 12. All characteristic oxidation peaks can be distinguished, similarly to the $0.01 \mathrm{M}$ concentrated solution (see Figure 4), while the position of the oxidation maxima was preserved upon the successive introduction of glucose into the electrolyte loading. However, the current density values corresponding to glucose oxidation were ca. 2 times smaller and in consequence the slope of the calibration curve decreased. Specifically, the slope equaled $5.5 \mu \mathrm{A} \mathrm{cm} \mathrm{cm}^{-2} \mathrm{mM}^{-1}$ for $0.1 \mathrm{M}$ sPBS compared to $22.7 \mu \mathrm{A} \mathrm{cm}^{-2} \mathrm{mM}^{-1}$ for $0.01 \mathrm{M}$. Thus, it can be stated that the increase of phosphates in the solution led to a decrease of electrochemical activity towards glucose. Such behavior was probably induced by the adsorption of phosphates on the gold surface, as has already been reported [41,42]. However, adsorption kinetics are slower for phosphates, compared to chlorides, and the reduction of catalytic activity is therefore smaller [42]. Although the sensitivity decreased, the adsorption of phosphates did not alter the glucose oxidation mechanism. Additionally, the second linear range was very wide (i.e., 2-20 mM), indicating the stability of the material in the presence of highly concentrated buffer. In contrast, no stability could be achieved in the case of $1 \mathrm{X}$ cPBS containing large amount of chlorides.
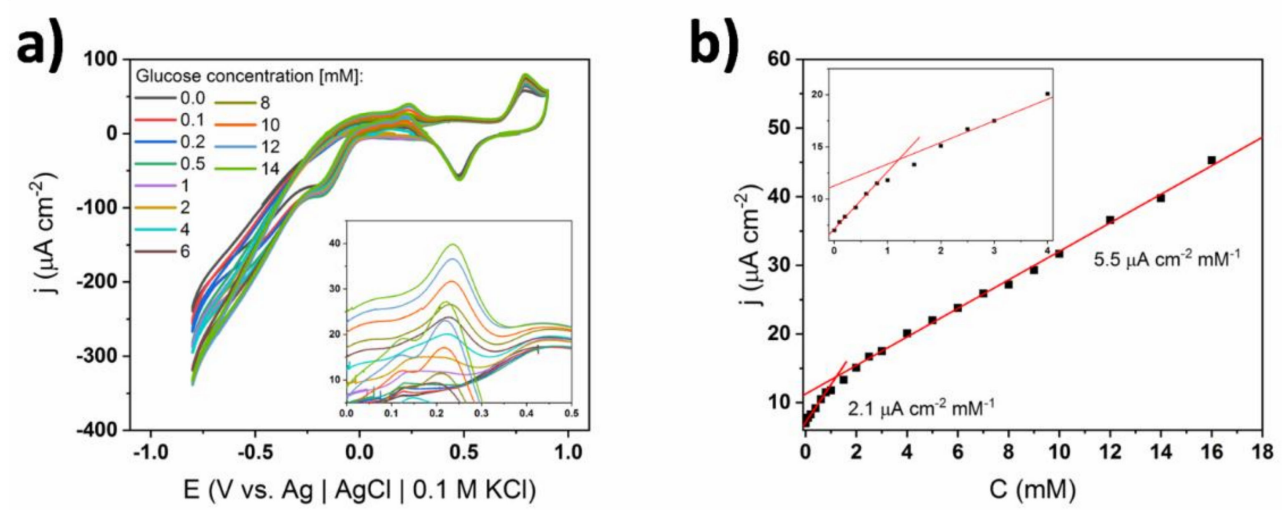

Figure 12. (a) Cyclic voltammograms of TiND|AuNP non-coated electrode registered for different glucose concentrations in $0.1 \mathrm{M}$ sPBS; inset-magnification of glucose oxidation peaks, (b) calibration curve based on glucose oxidation peak at $+0.35 \mathrm{~V}$. 
When the Nafion-coated electrode was exposed to 0.1 M sPBS, the shape of the CV curves (Figure 13) was significantly different from the analogous experiment carried out in $0.01 \mathrm{M}$ buffer. Firstly, the glucose oxidation peaks were well developed. This suggests that in the case of a higher supporting electrolyte concentration, diffusion is the dominant way of mass transport of $\mathrm{OH}^{-}$and no migration effect is observed [30,31]. In this experiment, the linear range on the calibration curve was the highest among all in this paper and was from 0.1 to $6 \mathrm{mM}$. Based on all considerations above, no transitions between mechanisms happened in the sPBS without chlorides. Moreover, when the supporting electrolyte was highly concentrated, no contribution of migration was present; therefore, the mass transport was governed purely by diffusion. Lastly, Nafion was a barrier preventing the adsorption of phosphates on the gold surface. This combination led to an optimal compromise between a wide linear range and decent sensitivity.
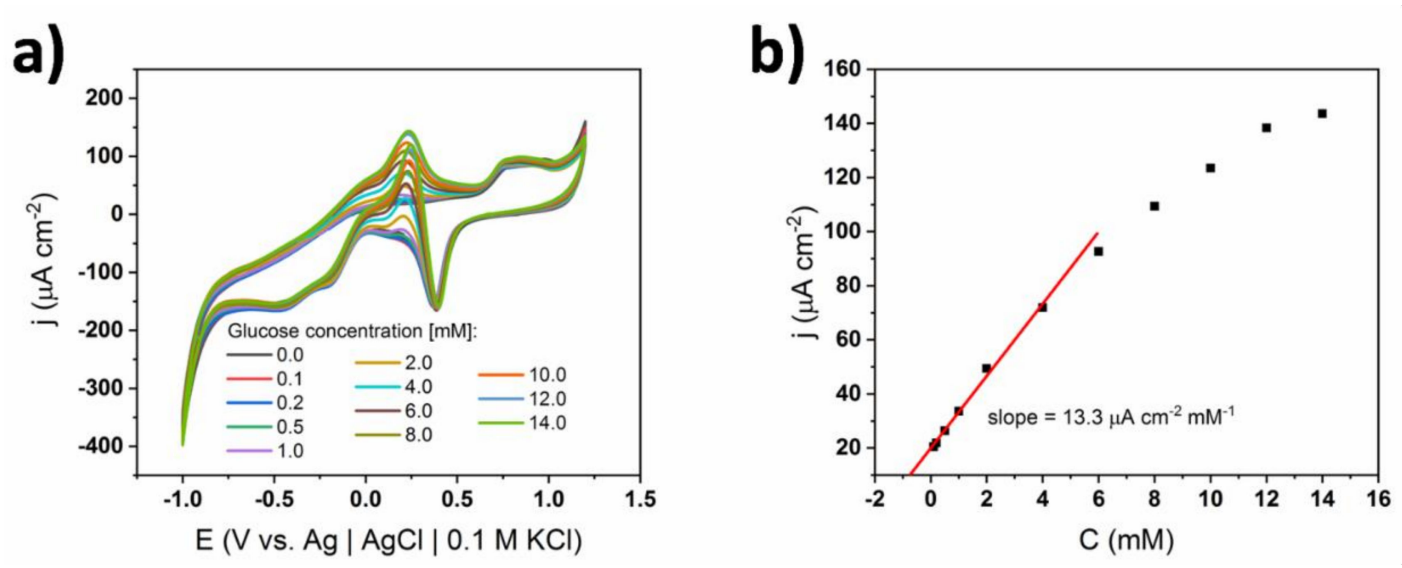

Figure 13. (a) Cyclic voltammograms of TiND|AuNP Nafion-coated electrode registered for different glucose concentrations in $0.1 \mathrm{M}$ sPBS, (b) calibration curve based on glucose oxidation peak at $+0.35 \mathrm{~V}$.

The set of sensing parameters determined for all examined conditions, including the electrode material and the buffer composition, is given in Table 4. Analyzing the values provided in the right column, it can be clearly seen that Nafion coating supports a widening of the linear range of electrochemical response regardless of the used liquid environment. This is connected with the abovementioned fact that, when Nafion is present on the surface, the apparent diffusion constant is smaller than for the bare electrode. Finally, it should be highlighted here that if the concentration of the supporting electrolyte and glucose are comparable, migration plays a significant role in the mass transport of hydroxyl ions. This is schematically presented in Figure 14.

Table 4. Comparison of slopes and linear ranges of bare and coated TiND|AuNP electrodes in different electrolytes.

\begin{tabular}{cccc}
\hline Electrode & Solution & Slope $\left[\boldsymbol{\mu} \mathbf{A ~} \mathbf{~ m}^{-\mathbf{2}} \mathbf{m M}^{-\mathbf{1}}\right]$ & Linear Range $[\mathbf{m M}]$ \\
\hline \multirow{2}{*}{ TiND|AuNP } & $0.1 \mathrm{X}$ cPBS & 29.3 & $0.1-0.5$ \\
\cline { 2 - 4 } & $0.01 \mathrm{M}$ sPBS & 22.7 & $0.1-2.0$ \\
\cline { 2 - 4 } & $0.1 \mathrm{M}$ sPBS & 5.5 & $0.1-0.8$ \\
\hline \multirow{2}{*}{ TiND|AuNP|Nafion } & $0.1 \mathrm{X}$ cPBS & 38.3 & $0.1-1.0$ \\
\cline { 2 - 4 } & $0.01 \mathrm{M}$ sPBS & 10.5 & $0.1-3.0$ \\
\cline { 2 - 4 } & $0.1 \mathrm{M}$ sPBS & 13.3 & $0.1-5.0$ \\
\hline
\end{tabular}




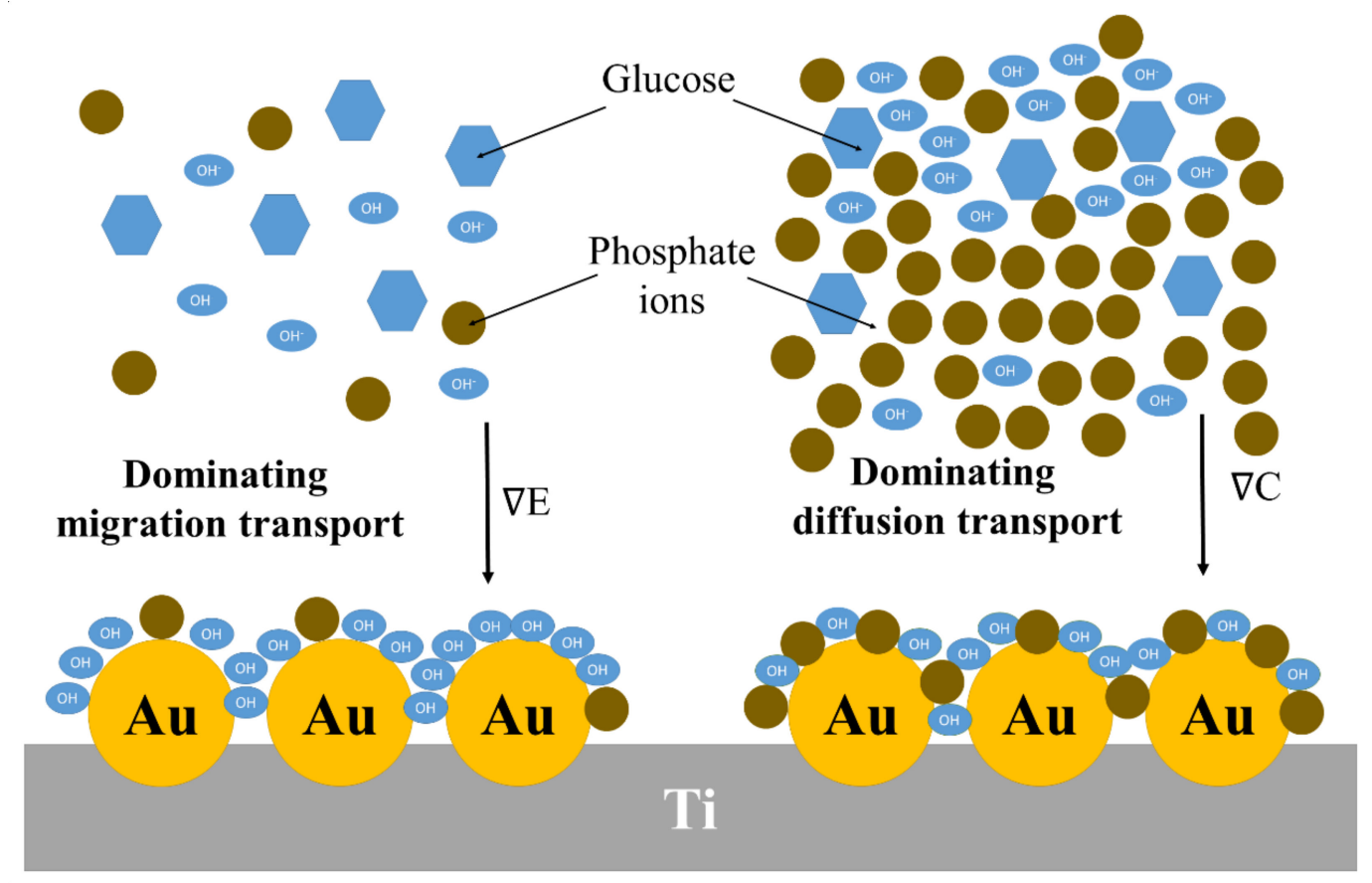

Figure 14. Schematic illustration of the effect of the electrolyte concentration on the transport of hydroxyl ions towards the electrode.

\section{Conclusions}

In this work, three factors influencing the mechanism of non-enzymatic glucose detection were investigated: the impact of the chloride content in the electrolyte, the presence of Nafion as a semi-permeable coating over the electrode surface, and the ionic conductivity of the electrolyte. The applied experimental procedure, including cyclic voltammetry studies, and the analysis of the impedance spectra recorded in various conditions, enabled the identification of changes in electrode behavior in the presence of various glucose levels. The performed measuring strategy enabled observation of three different phenomena for TiND|AuNP electrodes considered here as a model sensing platform with and without polymer coverage. The first of them is switching between the dominant mechanism describing glucose oxidation, namely from the IHOAM model to the chemisorption model. The second effect is connected to the presence of Nafion acting here as a selective membrane, and is called a bottleneck effect. Mass transport through the polymer is hampered due to blocking of channels and physical internal cross-linking. As a consequence, an increase in sensitivity and widening the linear range of the electrochemical response towards glucose are observed. The last, third effect is manifested in low concentrations of supporting electrolyte. It is based on the fact that the mass transport of hydroxyl ions is governed not only by diffusion, but also by migration. Those factors have a tremendous impact on the recorded cyclic voltammetry curves, and following that, the shape of the calibration curve and determined sensing parameters, namely the sensitivity and linear range. The approach proposed here, and the gathered results, shed light on the nature of glucose oxidation processes, and show that they can be far more complex for nanostructured electrodes coated with polymers than is commonly presented. Nevertheless, the provided explanations of these effects are treated as an initial stage towards further investigations within this still unexplored research area.

Author Contributions: Conceptualization, A.O., K.S. and K.G.; Investigation, A.O., J.K. and A.D.; Resources, K.S. and K.G.; Supervision, K.S. and K.G.; Funding acquisition, K.G.; Writing-Original draft, A.O.; Writing-Review \& editing, K.S. and K.G. All authors have read and agreed to the published version of the manuscript.

Funding: The work was financially supported by The National Centre for Research and Development via grant No LIDER/2/0003/L-8/16/NCBR/2017.

Conflicts of Interest: Authors have no conflict of interest. 


\section{References}

1. Hwang, D.-W.; Lee, S.; Seo, M.; Chung, T.D. Recent advances in electrochemical non-enzymatic glucose sensors-A review. Anal. Chim. Acta 2018, 1033, 1-34. [CrossRef] [PubMed]

2. Liu, N.; Xu, Z.; Morrin, A.; Luo, X. Low fouling strategies for electrochemical biosensors targeting disease biomarkers. Anal. Methods 2019, 11, 702-711. [CrossRef]

3. Park, S.; Song, Y.J.; Han, J.-H.; Boo, H.; Chung, T.D. Structural and electrochemical features of 3D nanoporous platinum electrodes. Electrochim. Acta 2010, 55, 2029-2035. [CrossRef]

4. Kim, S.H.; Choi, J.B.; Nguyen, Q.N.; Lee, J.M.; Park, S.; Chung, T.D.; Byun, J.-Y. Nanoporous platinum thin films synthesized by electrochemical dealloying for nonenzymatic glucose detection. Phys. Chem. Chem. Phys. 2013, 15, 5782. [CrossRef]

5. Ding, J.; Li, X.; Zhou, L.; Yang, R.; Yan, F.; Su, B. Electrodeposition of nickel nanostructures using silica nanochannels as confinement for low-fouling enzyme-free glucose detection. J. Mater. Chem. B 2020, 8 , 3616-3622. [CrossRef]

6. Liu, X.; Yang, W.; Chen, L.; Jia, J. Synthesis of copper nanorods for non-enzymatic amperometric sensing of glucose. Microchim. Acta 2016, 183, 2369-2375. [CrossRef]

7. Toghill,K.E.; Compton, R.G. Electrochemical non-enzymatic glucose sensors: A perspective and an evaluation. Intern. J. Electrochem. Sci. 2010, 5, 1246-1301.

8. Geelhood, S.J.; Horbett, T.A.; Ward, W.K.; Wood, M.D.; Quinn, M.J. Passivating protein coatings for implantable glucose sensors: Evaluation of protein retention. J. Biomed. Mater. Res. Part B Appl. Biomater. 2007, 81, 251-260. [CrossRef]

9. Li, L.; Chen, S.; Jiang, S. Protein interactions with oligo(ethylene glycol) (OEG) self-assembled monolayers: OEG stability, surface packing density and protein adsorption. J. Biomater. Sci. Polym. Ed. 2007, 18, 1415-1427. [CrossRef]

10. Lee, S.; Nam, J.H.; Kim, Y.J.; Cho, Y.J.; Kwon, N.H.; Lee, J.Y.; Kang, H.-J.; Kim, H.T.; Park, H.M.; Kim, S.; et al. Synthesis of PEO-based glucose-sensitive block copolymers and their application for preparation of superparamagnetic iron oxide nanoparticles. Macromol. Res. 2011, 19, 827-834. [CrossRef]

11. Feng, D.; Wang, F.; Chen, Z. Electrochemical glucose sensor based on one-step construction of gold nanoparticle-chitosan composite film. Sens. Actuators B Chem. 2009, 138, 539-544. [CrossRef]

12. Cao, H.; Yang, A.; Li, H.; Wang, S.; Li, S.; Kong, J.; Bao, X.; Yang, R. A non-enzymatic glucose sensing based on hollow cuprous oxide nanospheres in a Nafion matrix. Sens. Actuators B Chem. 2015, 214, 169-173. [CrossRef]

13. Mei, L.; Zhang, P.; Chen, J.; Chen, D.; Quan, Y.; Gu, N.; Zhang, G.; Cui, R. Non-enzymatic sensing of glucose and hydrogen peroxide using a glassy carbon electrode modified with a nanocomposite consisting of nanoporous copper, carbon black and nafion. Microchim. Acta 2016, 183, 1359-1365. [CrossRef]

14. Hu, Y.; Liang, B.; Fang, L.; Ma, G.; Yang, G.; Zhu, Q.; Chen, S.; Ye, X. Antifouling Zwitterionic Coating via Electrochemically Mediated Atom Transfer Radical Polymerization on Enzyme-Based Glucose Sensors for Long-Time Stability in $37^{\circ} \mathrm{C}$ Serum. Langmuir 2016, 32, 11763-11770. [CrossRef]

15. Yang, W.; Xue, H.; Carr, L.R.; Wang, J.; Jiang, S. Zwitterionic poly(carboxybetaine) hydrogels for glucose biosensors in complex media. Biosens. Bioelectron. 2011, 26, 2454-2459. [CrossRef] [PubMed]

16. Yang, J.; Liang, X.; Cui, L.; Liu, H.; Xie, J.; Liu, W. A novel non-enzymatic glucose sensor based on Pt3Ru1 alloy nanoparticles with high density of surface defects. Biosens. Bioelectron. 2016, 80, 171-174. [CrossRef]

17. Kokkindis, G.; Leger, J.; Lamy, C. Structural effects in electrocatalysis: Oxidation of D-glucose on pt (100), (110) and (111) single crystal electrodes and the effect of upd adlayers of $\mathrm{Pb}, \mathrm{Tl}$ and Bi. J. Electroanal. Chem. Interfacial Electrochem. 1988, 242, 221-242. [CrossRef]

18. Popović, K.; Marković, N.; Tripković, A.; Adžić, R. Structural effects in electrocatalysis: Oxidation of D-glucose on single crystal platinum electrodes in alkaline solution. J. Electroanal. Chem. Interfacial Electrochem. 1991, 313, 181-199. [CrossRef]

19. Niu, X.; Lan, M.; Zhao, H.; Chen, C. Well-Dispersed Pt Cubes on Porous Cu Foam: High-Performance Catalysts for the Electrochemical Oxidation of Glucose in Neutral Media. Chem. A Eur. J. 2013, 19, 9534-9541. [CrossRef]

20. Guo, M.; Hong, H.; Tang, X.; Fang, H.; Xu, X. Ultrasonic electrodeposition of platinum nanoflowers and their application in nonenzymatic glucose sensors. Electrochim. Acta 2012, 63, 1-8. [CrossRef] 
21. Grochowska, K.; Szkoda, M.; Karczewski, J.; Śliwiński, G.; Siuzdak, K. Ordered titanium templates functionalized by gold films for biosensing applications-Towards non-enzymatic glucose detection. Talanta 2017, 166, 207-214. [CrossRef] [PubMed]

22. Olejnik, A.; Siuzdak, K.; Karczewski, J.; Grochowska, K. A Flexible Nafion Coated Enzyme-free Glucose Sensor Based on Au-dimpled Ti Structures. Electroanalysis 2019, 32, 323-332. [CrossRef]

23. Olejnik, A.; Karczewski, J.; Dołęa, A.; Siuzdak, K.; Grochowska, K. Novel approach to interference analysis of glucose sensing materials coated with Nafion. Bioelectrochemistry 2020, 135, 107575. [CrossRef] [PubMed]

24. Vaidya, R.; Atanasov, P.; Wilkins, E. Effect of interference on the performance of glucose enzyme electrodes using Nafion ${ }^{\circledR}$ coatings. Med. Eng. Phys. 1995, 17, 416-424. [CrossRef]

25. Mauritz, K.A.; Moore, R.B. State of understanding of Nafion. Chem. Rev. 2004, 104, 4535-4586. [CrossRef]

26. Bondarenko, A.S.; Ragoisha, G.A. In Progress of the in Chemometrics Research. Pomerantsev, A.L., Ed.; Nova Science Publishers: New York, NY, USA, 2005; pp. 89-102. Available online: http://www.abc.chemistry. bsu.by/vi/analyser/ (accessed on 20 August 2020).

27. Kim, J.-S.; Pyun, S.-I. Comparison of transmissive permeable and reflective impermeable interfaces between electrode and electrolyte. J. Solid State Electrochem. 2011, 15, 2447-2452. [CrossRef]

28. Kollath, V.O.; Karan, K. New molecular scale insights into the ?-transition of Nafion@thin films from variable temperature ATR-FTIR spectroscopy. Phys. Chem. Chem. Phys. 2016, 18, 26144-26150. [CrossRef]

29. Menegazzo, F.; Manzoli, M.; Chiorino, A.; Boccuzzi, F.; Tabakova, T.; Signoretto, M.; Pinna, F.; Pernicone, N. Quantitative determination of gold active sites by chemisorption and by infrared measurements of adsorbed CO. J. Catal. 2006, 237, 431-434. [CrossRef]

30. Galus, Z. Teoretyczne Podstawy Elektroanalizy Chemicznej; Państwowe Wydawnictwo Naukowe: Warsaw, Poland, 1977.

31. Bard, A.J.; Faulkner, L.R. Fundamentals and applications. Electrochem. Methods 2001, 2, 580-632.

32. Lasia, A. Electrochemical impedance spectroscopy and its applications. In Modern Aspects of Electrochemistry; Springer: Boston, MA, USA, 2002; pp. 143-248.

33. Hsu, C.H.; Mansfeld, F. Technical Note:Concerning the Conversion of the Constant Phase Element Parameter Y0into a Capacitance. Corrosion 2001, 57, 747-748. [CrossRef]

34. Arjona, N.; Arriaga, L.; Guerra-Balcázar, M.; Trejo, G.; Ledesma-García, J. An electrokinetic-combined electrochemical study of the glucose electro-oxidation reaction: Effect of gold surface energy. RSC Adv. 2016, 6, 15630-15638. [CrossRef]

35. Xu, X.; Makaraviciute, A.; Pettersson, J.; Zhang, S.-L.; Nyholm, L.; Zhang, Z. Revisiting the factors influencing gold electrodes prepared using cyclic voltammetry. Sens. Actuators B Chem. 2019, 283, 146-153. [CrossRef]

36. Ugo, P.; Moretto, L.M. Ion Exchange Voltammetry. In Ion Exchange Technology I; Springer Science and Business Media LLC: Berlin/Heidelberg, Germany, 2012; pp. 403-435.

37. Espenscheid, M.W.; Ghatak-Roy, A.R.; Moore, R.B.; Penner, R.M.; Szentirmay, M.N.; Martin, C.R. Sensors from polymer modified electrodes. J. Chem. Soc. Faraday Trans. 1 Phys. Chem. Condens. Phases 1986, 82, 1051-1070. [CrossRef]

38. Hannoun, B.J.M.; Stephanopoulos, G. Diffusion coefficients of glucose and ethanol in cell-free and cell-occupied calcium alginate membranes. Biotechnol. Bioeng. 1986, 28, 829-835. [CrossRef]

39. Nakanishi, K.; Adachi, S.; Yamamoto, S.; Matsuno, R.; Tanaka, A.; Kamikubo, T. Diffusion of Saccharides and Amino Acids in Cross-linked Polymers. Agric. Boil. Chem. 1977, 41, 2455-2462. [CrossRef]

40. Whiteley, L.D.; Martin, C.R. Fresh look at transport in perfluorosulfonate ionomers: Ultramicroelectrode investigations of Nafion and the Dow ionomers. J. Phys. Chem. 1989, 93, 4650-4658. [CrossRef]

41. Yaguchi, M.; Uchida, T.; Motobayashi, K.; Osawa, M. Speciation of Adsorbed Phosphate at Gold Electrodes: A Combined Surface-Enhanced Infrared Absorption Spectroscopy and DFT Study. J. Phys. Chem. Lett. 2016, 7, 3097-3102. [CrossRef]

42. Hsiao, M.; Adzic, R.; Yeager, E. The effects of adsorbed anions on the oxidation of D-glucose on gold single crystal electrodes. Electrochim. Acta 1992, 37, 357-363. [CrossRef]

(C) 2020 by the authors. Licensee MDPI, Basel, Switzerland. This article is an open access article distributed under the terms and conditions of the Creative Commons Attribution (CC BY) license (http://creativecommons.org/licenses/by/4.0/). 